\title{
Assessment of the effectiveness of obstructive sleep apnea treatment using optical coherence tomography to evaluate reti- nal findings
}

\author{
Gloria Tejero-Garcés ${ }^{1}$, Francisco J. Ascaso ${ }^{2}$, Paula Casas ${ }^{3}$, Maria I. Adiego ${ }^{4}$, Peter Baptista ${ }^{5}$, Carlos $\mathrm{O}^{\prime}$ Connor- \\ Reina $^{6}$, Eugenio Vicente ${ }^{4}$, Guillermo Plaza ${ }^{7,8^{*}}$.
}

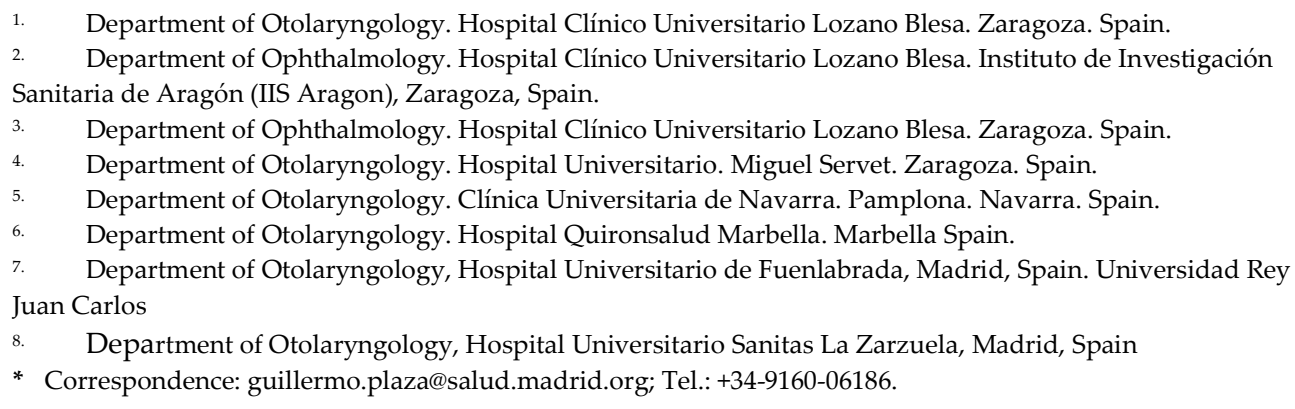

\begin{abstract}
Retinal findings may change in patients with obstructive sleep apnea syndrome (OSAS). The present study aims to evaluate several retinal findings such as macula layer thickness, peripapillary retinal nerve fiber layer, and the optic nerve head in patients with OSAS using optical coherence tomography (OCT) and monitor the result of several types of treatment of OSAS with OCT. A prospective comparative study was designed. Patients were recruited at a Sleep Unit of a University Hospital and underwent comprehensive ophthalmological examinations. Following exclusion criteria, fifty-two patients with OSAS were finally included. Patients were examined by OCT twice: first, before treatment; secondly, after six months of treatment. In mild-moderate patients, where retinal swelling has been demonstrated, retinal thicknesses decreased [fovea $(p=0.026)$, as well as inner ring macula $(p=0.007)$, outer ring macula $(p=0.015)$, and macular volume $(p=0.015)]$. In severe patients, where retinal atrophy had been observed, retinal thickness increased [fovea $(\mathrm{p}<0.001)]$. No statistically significant differences in efficacy between treatments were demonstrated. In conclusion, OCT can evaluate the retina in patients with OSAS and help monitor results after treatment. In severe OSAS, retinal thickness increased six months after treatment.
\end{abstract}

Keywords: Retina; Retinal nerve fiber layer; Obstructive sleep apnea syndrome; Optical coherence tomography; OCT; CPAP; Upper airway surgery.

\section{Introduction}

Obstructive sleep apnea syndrome (OSAS) is one of the most frequent sleep disorders in our population [1]. A recent estimation has shown that $13 \%$ of middle-aged men and $5 \%$ of middle-aged women are affected. An increase in prevalence by 30\% between 1990 and 2010 was seen [2]. Continuous and maintained oxygen desaturation during sleep results in metabolic, cardiovascular, and neuropsychiatric consequences that impact quality of life and increase mortality [1,3]. Intermittent hypoxia enhances a sympathetic response and oxidative stress that result in systemic and local inflammation [4]. This high incidence and severe comorbidity make an early diagnosis essential $[1,5]$. 
Currently, sleep studies, such as polysomnography and cardio-respiratory polygraphy, allow the diagnosis and follow-up treatment of OSAS [1,5]. However, these techniques are expensive and not widely available, generating high demand and long waiting lists.

The most accepted marker for this disease's severity is the sleep studies apnea-hypopnea index (AHI). But AHI only shows the number of times a patient presents respiratory events but does not measure its effect on the body, which can vary between patients with similar AHI [1,5-7].

The retina, a part of the central nervous system, may express changes during chronic and intermittent hypoxia in OSAS patients. Optical coherence tomography (OCT) has been used in various neurological disorders to study the retina [8-11]. In addition, it provides fast and non-invasive information of macula layer thickness, peripapillary retinal nerve fiber layer (RNFL) and the optic nerve head (ONH)[12]. Some studies have already demonstrated retinal changes in OSAS patients, such as increased thickness in mild-moderate OSAS patients, a so-called inflammation, or a decrease in retinal thickness in severe OSAS patients, a degenerative neurological process [13-27].

Furthermore, OCT has recently been used to monitor the effect of CPAP or surgical treatment for OSAS, showing how OCT is useful for checking improvements in the retina and optic nerve measurements [28-31].

In the present study, we aimed to evaluate OCT as a tool to monitor response to therapy through retinal changes such as macula thickness, RNFL, and ONH, after CPAP therapy and after surgical treatment in two related groups of patients with OSAS, and to review the current role of OCT as a monitoring tool after OSAS treatment through the literature.

\section{Materials and Methods}

This research was approved by the Institutional Review Board and Ethics Committee of a University Hospital and planned as a prospective non-randomized comparative study. Informed consent was obtained from all participants. The present study included patients presenting to the Sleep Disorders Unit of Hospital Universitario-Miguel Servet. (Zaragoza. Spain). All patients complained of snoring, witnessed apnea episodes, or excessive daytime sleepiness for over two years. A complete otolaryngologic exam was performed including nasopharyngolaryngoscopy, and ophthalmological examination with OCT measurements.

Each subject underwent an attended overnight cardio-respiratory polygraphy (Bitmed ${ }^{\circledR}$ NGX320 Sibel) conducted by the Pulmonology Department at the same University Hospital. The apnea/hypopnea index (AHI) was calculated as the total number of apneas and hypopneas per hour of electroencephalographic sleep. OSAS severity was classified as mild for an AHI between 5 and 15, moderate for an AHI greater than 15 and less than 30, and severe for an AHI greater than 30. All studies were scored and read by a physician unaware of the study's aim and, therefore, masked to patients' ophthalmic evaluation results.

The ophthalmologic evaluation included best-corrected visual acuity (BCVA), slitlamp biomicroscopy, Perkins applanation tonometry, gonioscopy with a four mirror contact lens, and fundoscopy. OCT was performed with the time-domain optical coherence tomography (TD-OCT) Stratus of Carl Zeiss Meditec Inc., Dublin, CA, USA, following 1 $\%$ tropicamide instillation for dilation of the pupils' process [5]. Only high-quality images (signal strength 27 ) were included $[5,20]$. Each patient underwent scans to measure macular parameters (foveal thickness, inner ring thickness, outer ring thickness and macular volume), peripapillary RNFL parameters (average thickness and superior, inferior, temporal and nasal quadrant thicknesses) and ONH morphometric parameters [vertical integrated rim area (VIRA), horizontal integrated rim width (HIRW), disc area, cup area, rim area, and cup/disc ratios] (Figure 1), all during the same visit. 


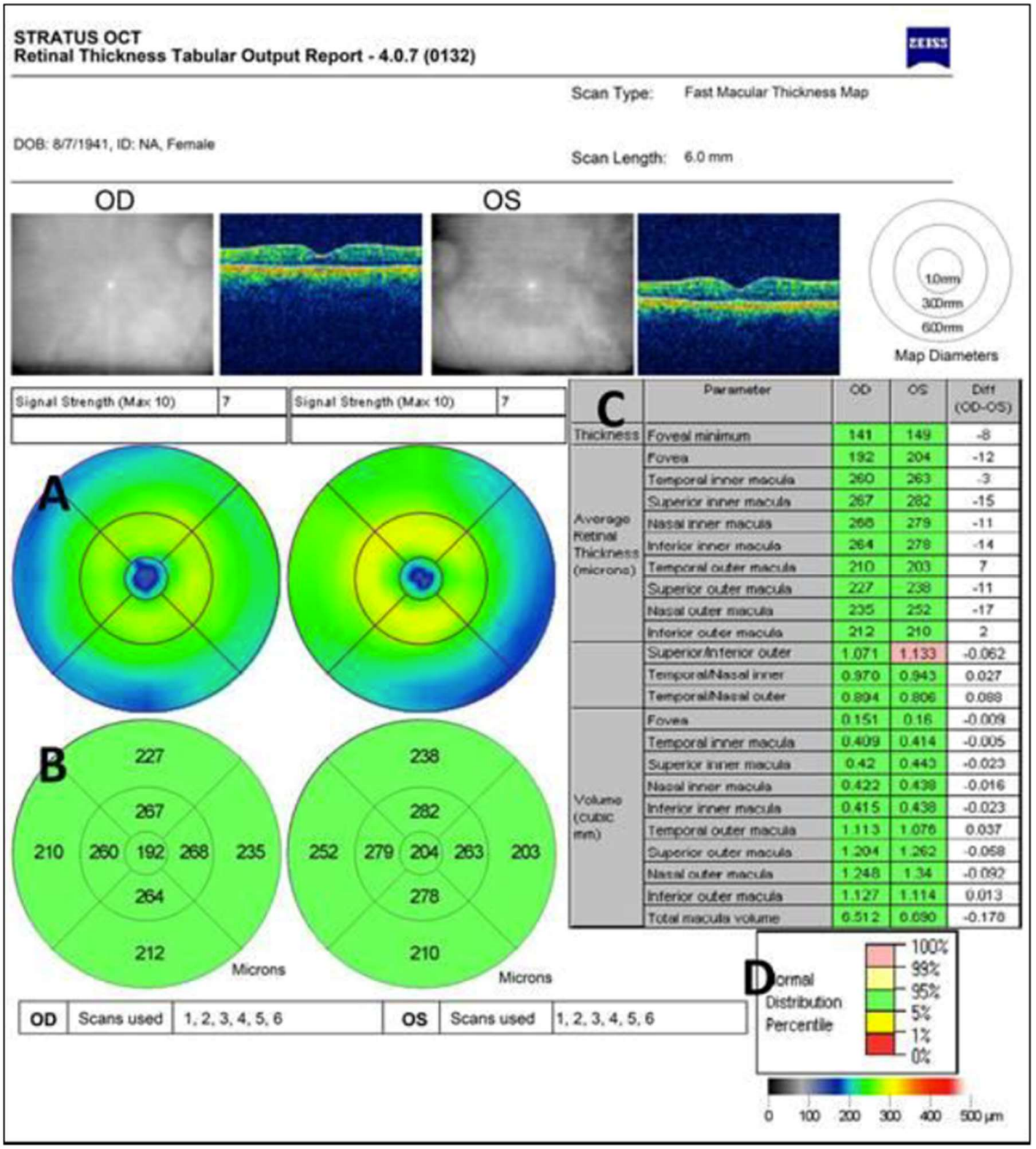

Figure 1. - Macular measures with Stratus OCT. A: Retinal Thickness/Volume. B: Average thickness (mm). C: Thickness and Volume values. D: Normative data to compare.

Both eyes of everyone were included, except when an exclusion criteria appeared in one eye, assuming that OSAS influence could be asymmetric, following Shrier et al. [32]

Exclusion criteria included patients that suffered from ocular disease (Humphrey visual field defects compatible with glaucoma or intraocular pressure (IOP) $>21 \mathrm{mmHg}$, refractive error over 4 spherical diopters and 3 diopters of astigmatism, posterior segment pathology or media opacification, ocular surgery or trauma) or systemic disorders (uncontrolled systemic pathology, such as diabetes mellitus or arterial hypertension; mental, neurodegenerative or chronic inflammatory disorders) which could damage their retina or could prevent an appropriate study, as well as those who would only be treated with dietetic and hygienic measures, or had been previously treated with CPAP or surgery.

Treatment that consisted of CPAP therapy, surgery, or a combination of both was given once patients had completed the OCT examination. Each treatment was specifically 
chosen according to the patient's AHI, comorbidity, physical examination, body mass in$\operatorname{dex}(\mathrm{BMI})$, and preference, following current guidelines [5].

A well-trained technician conducted individual training and the optimal pressure of CPAP therapy, as recommended [1]. Patients were encouraged to sleep with the PAP therapy to reach adequate adherence. Therapy adherence was defined as using PAP therapy for an average of four hours a night for at least $70 \%$ of the nights. Only patients with PAP adherence were included for comparing outcomes.

Patients were selected according to ENT and fibroscopic examination and severity of OSAS disease according to PSG parameters for the surgical group. In all cases septoplasty and palatopharyngoplasty were performed, and multilevel surgery was done if required. $\mathrm{CPAP}$ was also added for those cases not improving after surgery, having AHI $>15$ three months after surgery.

After a minimum of six months of treatment, all patients underwent final cardiorespiratory polygraphy and a complete bilateral ophthalmological examination.

Data analysis was conducted using SPSS software version 22.0 (SPSS, Inc, Chicago, IL, USA). Values are presented as mean \pm standard deviation (SD) and percentages, expressed in microns $(\mu \mathrm{m})$ for the peripapillary RNFL thickness and macular retinal thickness and in $\mathrm{mm} 3$ for macular volume. Once normal distribution and homogeneity were confirmed with Kolmogorov-Smirnov and Levene tests, respectively, a comparison between means was carried out using a paired t-test and ANOVA test, through the General Linear Model (GLM) procedure for more than two groups.

Paired t-test was used to compare initial and control OCT data, constantly comparing the same eye side from baseline to control measures.

The correlation between AHI and significant ophthalmologic variables was evaluated using Pearson's linear correlation coefficient. A p-value $<0.05$ was considered statistically significant. Sample size was defined in 92 eyes to be evaluated, with an error range of $3 \%$ for a confidence level of $95 \%$ under the assumption of maximum variance $(p=q=0.5)$.

\section{Results}

Sixty patients (120 eyes) were initially recruited. Six patients refused to continue at some point during the study, leaving 54 patients to be analyzed. Of a total of 108 eyes that were examined, ten eyes of ten different patients had to be excluded due to previous ophthalmological pathologies. Finally, 98 eyes from 52 patients were included in the study.

Among our patients, $42(80.7 \%)$ were male, and the mean age was $50.1 \pm 12.6$ years. According to the severity of OSAS, four patients (7.7\%) were mild OSAS (AHI $\geq 5$ ), 19 $(36.6 \%)$ were moderate OSAS (AHI $\geq 15)$ and $29(55.7 \%)$ were severe OSAS (AHI $\geq 30)$. They were grouped into mild-moderate ( 23 patients) or severe cases ( 29 patients) for statistical purposes.

Moreover, $32.7 \%$ had controlled arterial hypertension, $7.7 \%$ controlled diabetes mellitus, $28.8 \%$ were smokers of $<5$ pack/year, and $26.8 \%$ former smokers. $13.5 \%$ had a normal BMI, $44.2 \%$ were overweight, and $42.3 \%$ had obesity. Mean BMI was 28.8 in mildmoderate OSAS and 29.8 in severe OSAS.

When describing the three groups of treatment, 17 (32.7\%) of our patients were treated with CPAP, $15(28.8 \%)$ with surgery, and 20 (38.5\%) underwent a combination of $\mathrm{CPAP}$ and surgery. Initial AHI was significantly lower in those cases only treated with surgery $(27.1+/-15.3)$, as compared to those treated with CPAP $(46.5+/-20.4)$ or a combination of CPAP and surgery $(54.1+/-29,3)$. Furthermore, initial AHI was significantly worse in severe OSAS cases that were treated with a combination of CPAP and surgery than those only treated with surgery (69.7 vs. 43.2 ; table 1$)$.

Table 1. AHI changes after treatment. GLM: Means \pm SD and statistical contrasts of AHI between surgery and combination of CPAP and surgery in both OSA groups (35 patients). GLM: Means \pm SD and statistical contrasts of AHI between surgery and combination of CPAP and surgery in both OSA groups (35 patients). GLM: General Linear Model; SD: standard deviation; df: degrees of freedom; eta²: partial eta² (effect size); p: level of statistical significance. 


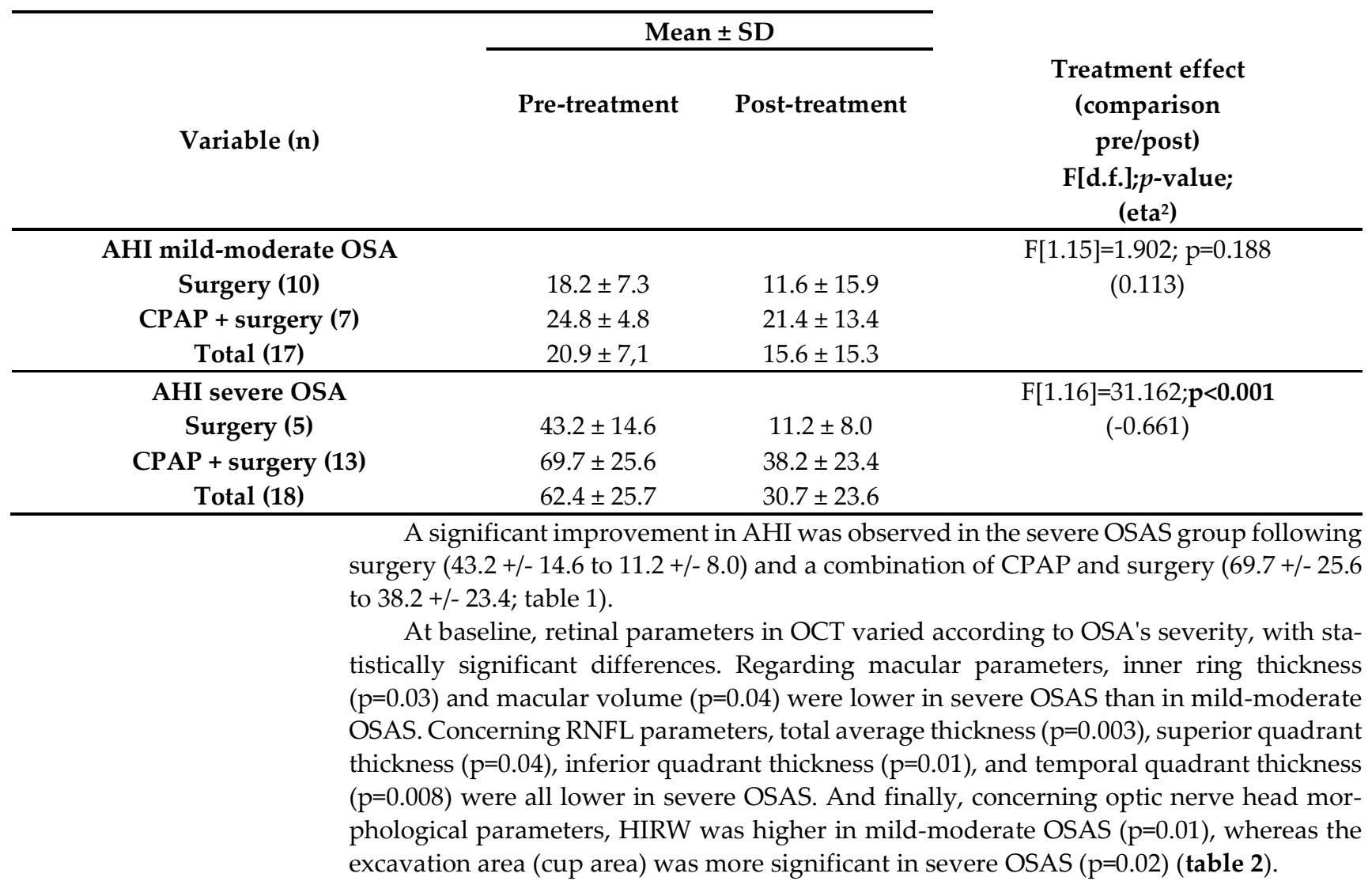

Table 2. Comparison between baseline retinal parameters of both OSA groups (98 eyes). SD: standard deviation; VIRA: vertical integrated rim area; HIRW: horizontal integrated rim width; Cup/disc ratio: excavation/disc ratios; p: level of statistical significance.

\begin{tabular}{cccc}
\hline Variable & \multicolumn{2}{c}{ Mean \pm SD } & \\
\cline { 2 - 3 } & $\begin{array}{c}\text { Mild/moderate OSA } \\
(\mathbf{n}=\mathbf{4 1})\end{array}$ & $\begin{array}{c}\text { Severe OSA } \\
(\mathbf{n}=\mathbf{5 5})\end{array}$ & \\
\hline Foveal thickness $(\mu \mathrm{m})$ & $214.6 \pm 22.28$ & $206.7 \pm 27.38$ & 0.138 \\
\hline Inner ring macular thickness $(\mu \mathrm{m})$ & $281.4 \pm 13.4$ & $271.9 \pm 15.85$ & $\mathbf{0 . 0 0 3}$ \\
Outer ring macular thickness $(\mu \mathrm{m})$ & $241.3 \pm 1.17$ & $236.4 \pm 13.55$ & 0.054 \\
Macular volume $(\mathrm{mm} 3)$ & $7 \pm 0.33$ & $6.9 \pm 0.39$ & $\mathbf{0 . 0 4 1}$ \\
\hline RNFL average thickness $(\mu \mathrm{m})$ & $102.3 \pm 9.06$ & $96.1 \pm 1.27$ & $\mathbf{0 . 0 0 3}$ \\
RNFL superior quadrant thickness $(\mu \mathrm{m})$ & $129.1 \pm 12.56$ & $122.3 \pm 18.21$ & $\mathbf{0 . 0 4 4}$ \\
RNFL nasal quadrant thickness $(\mu \mathrm{m})$ & $75.7 \pm 16.27$ & $73.3 \pm 15.02$ & 0.458 \\
RNFL inferior quadrant thickness $(\mu \mathrm{m})$ & $128.6 \pm 16.99$ & $120.1 \pm 16.08$ & $\mathbf{0 . 0 1 4}$ \\
RNFL temporal quadrant thickness $(\mu \mathrm{m})$ & $75.6 \pm 11.3$ & $68.7 \pm 13.04$ & $\mathbf{0 . 0 0 8}$ \\
\hline VIRA $(m m 3)$ & $0.8 \pm 0.51$ & $0.6 \pm 0.31$ & 0.102 \\
HIRW $(m m 2)$ & $2 \pm 0.3$ & $1.8 \pm 0.28$ & $\mathbf{0 . 0 1}$ \\
Disc area $(m m 2)$ & $2.8 \pm 0.69$ & $2.6 \pm 0.56$ & 0.115 \\
Cup area $(m m 2)$ & $0.5 \pm 0.52$ & $0.9 \pm 1.06$ & $\mathbf{0 . 0 2 8}$ \\
Rim area $(m m 2)$ & $2.1 \pm 0.7$ & $1.9 \pm 0.81$ & 0.279 \\
Cup/disc area ratio & $0.2 \pm 0.18$ & $0.3 \pm 0.27$ & 0.078 \\
Cup/disc horizontal ratio & $0.4 \pm 0.19$ & $0.5 \pm 0.24$ & 0.123 \\
Cup/disc vertical ratio & $0.4 \pm 0.17$ & $0.5 \pm 0.24$ & 0.108 \\
\hline
\end{tabular}


In the mild-moderate patients OSAS group, where retinal swelling has been demonstrated, all macular measurements in OCT showed a statistically significant decrease after six months of treatment (table 3 and figure 2 ).

Table 3. Evolution of macular parameters in the mild-moderate OSA group (43 eyes evaluated from 23 patients). GLM: General Linear Model; SD: standard deviation; df: degrees of freedom; eta2: partial eta2 (effect size); p: level of statistical significance.

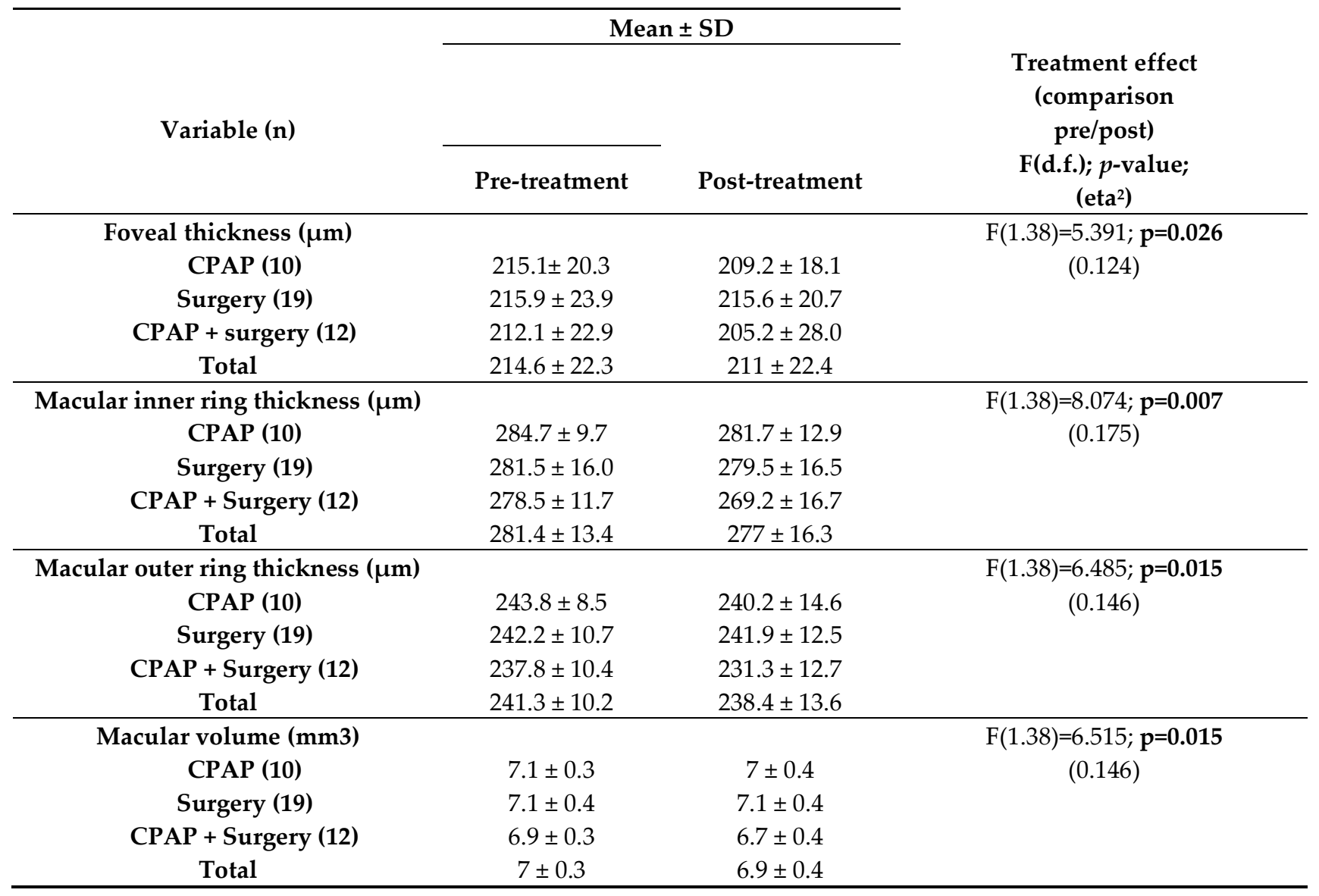



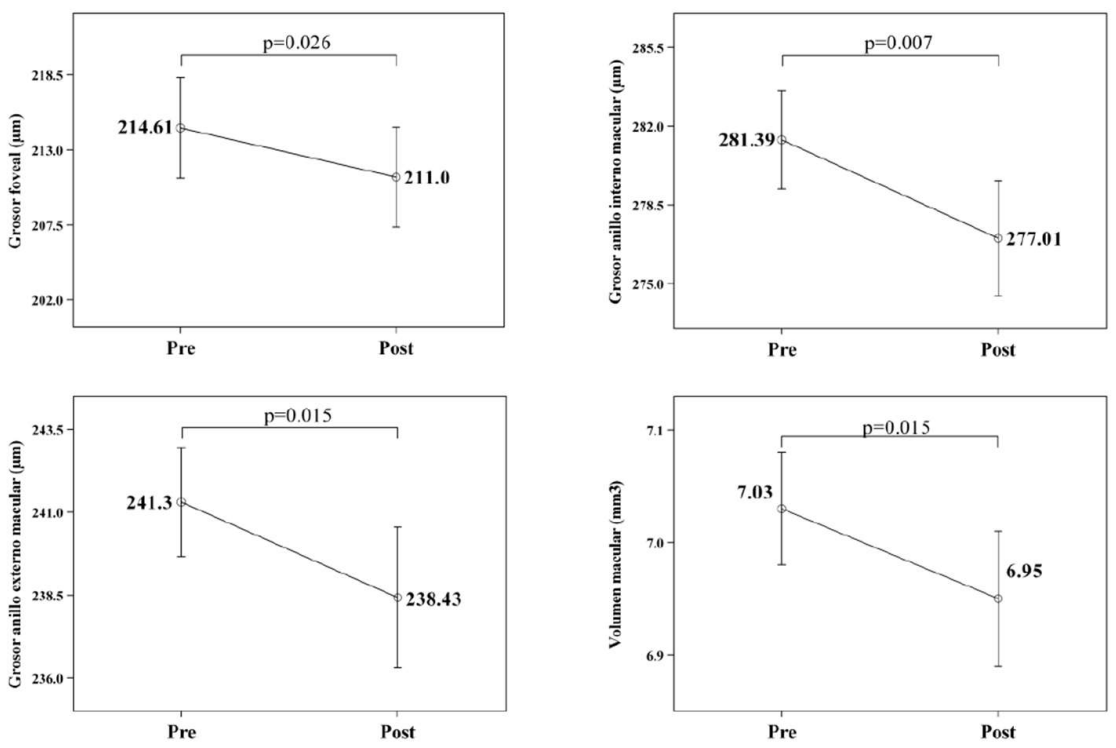

Figure 2. Significant changes in retinal OCT findings after treatment in mild-moderate OSA (43 eyes evaluated from 23 patients), showing a significant decrease in average foveal thickness, inner and outer ring thickness and macular volume.

Every RNFL parameter decreased but not in a statistically significant way (See table in supplementary material), and none of the $\mathrm{ONH}$ morphometric parameters showed changes following treatment.

In the severe OSAS group, where retinal atrophy had been observed, thickness increased, and all macular parameters increased their value. However, only the foveal thickness increase was statistically significant (table 4 and figure 3). All RNFL thicknesses increased their value. Still, only the average thickness increased in a statistically significant way (See table in supplementary material, and figure 3), and finally, no changes were observed in morphometric ONH parameters.

Table 4. Evolution of macular parameters in the severe OSA group (55 eyes evaluated from 29 patients). GLM: General Linear Model; SD: standard deviation; df: degrees of freedom; eta2: partial eta2 (effect size); p: level of statistical significance.

\begin{tabular}{|c|c|c|c|}
\hline \multirow{3}{*}{ Variable (n) } & \multicolumn{2}{|c|}{ Mean \pm SD } & \multirow{2}{*}{$\begin{array}{c}\text { Treatment effect } \\
\text { (comparison } \\
\text { pre/post) }\end{array}$} \\
\hline & & & \\
\hline & $\begin{array}{c}\text { Pre- } \\
\text { treatment }\end{array}$ & $\begin{array}{c}\text { Post- } \\
\text { treatment }\end{array}$ & $\begin{array}{c}\text { F(f.g.); } p \text {-value } \\
\left(\text { eta }^{2}\right)\end{array}$ \\
\hline Foveal thickness ( $\mu \mathrm{m})$ & & & $\mathrm{F}(1.50)=16.780 ; \mathrm{p}<0.001$ \\
\hline CPAP (22) & $215.2 \pm 35.7$ & $225.5 \pm 38.1$ & $(0.251)$ \\
\hline Surgery (10) & $192.8 \pm 15.6$ & $204.3 \pm 24.6$ & \\
\hline CPAP + surgery (23) & $204.5 \pm 17.9$ & $207.6 \pm 20.2$ & \\
\hline Total & $206.7 \pm 27.4$ & $214.4 \pm 30.6$ & \\
\hline Macular inner ring thickness $(\mu \mathrm{m})$ & & & $F(1.50)=0.267 ; p=0.608$ \\
\hline CPAP (22) & $275.2 \pm 18.2$ & $275.6 \pm 19.2$ & $(0.005)$ \\
\hline Surgery (10) & $260.4 \pm 12.5$ & $261.8 \pm 13.9$ & \\
\hline CPAP + surgery (23) & $273.8 \pm 12.3$ & $274.5 \pm 13.3$ & \\
\hline Total & $271.9 \pm 15.8$ & $272.6 \pm 16.7$ & \\
\hline Macular outer ring thickness $(\mu \mathrm{m})$ & & & $\mathrm{F}(1.50)=1.438 ; \mathrm{p}=0.236$ \\
\hline CPAP (22) & $237.5 \pm 16.3$ & $237.7 \pm 17.9$ & $(0.028)$ \\
\hline
\end{tabular}




\begin{tabular}{cccc} 
Surgery (10) & $230.7 \pm 8$ & $235.2 \pm 11.5$ & \\
CPAP + surgery (23) & $237.8 \pm 12.2$ & $238.9 \pm 10.1$ & \\
Total & $236.3 \pm 13.6$ & $237.7 \pm 13.9$ & $\mathrm{~F}(1.50)=0.834 ; \mathrm{p}=0.365$ \\
Macular volume (mm3) & & & $(0.016)$ \\
CPAP (22) & $6.9 \pm 0.5$ & $6.8 \pm 0.5$ & \\
Surgery (10) & $6.6 \pm 0.2$ & $6.8 \pm 0.3$ & \\
CPAP + surgery (23) & $6.9 \pm 0.3$ & $6.9 \pm 0.3$ & \\
Total & $6.9 \pm 0.4$ & $6.9 \pm 0.4$ & \\
\hline
\end{tabular}
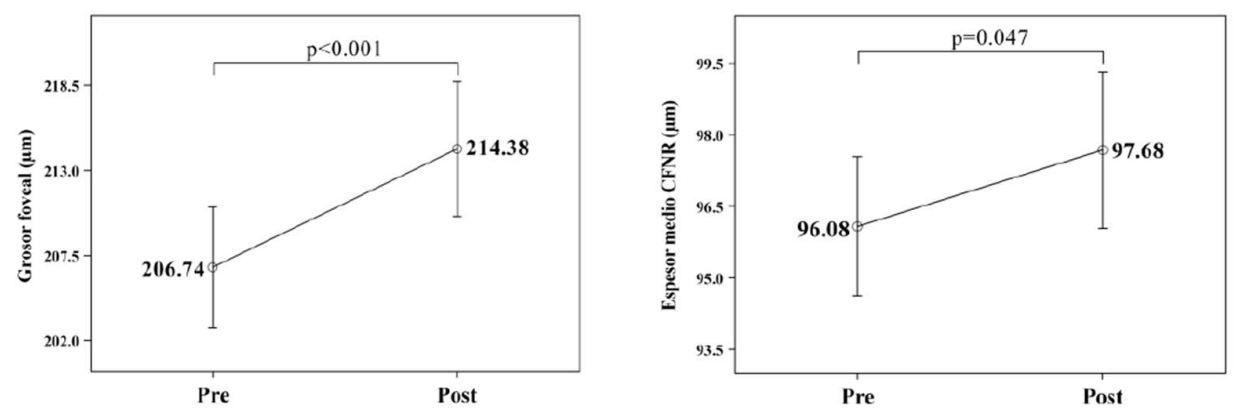

Figure 3. Significant changes in retinal OCT findings after treatment in severe OSA (55 eyes evaluated from 29 patients), showing a significant increase in average foveal and RFNL thickness.

In summary, analyzing OCT changes after CPAP and/ or surgery, we found a substantial improvement in foveal thickness and RNFL average thicknesses in both groups. Still, we could not see a significant difference between them. Lastly, we calculated the correlation between AHI and OCT, obtaining no relationship between changes in retinal parameters and changes in the AHI after six months of treatment.

\section{Discussion}

Intermittent airway obstruction in OSAS leads to hypoxia, hypercapnia, and changes in intrathoracic pressure. Consequently, perfusion alterations due to autonomic, hemodynamic, humoral, and neuroendocrine changes may affect the brain of OSAS patients [811]. A straightforward way of studying the neurological consequences of this entity could be reached through the information of the retinal structure in OSAS patients [25,33].

OCT is a technique that provides real measurements of the macula, peripapillary retinal layers, and the optic nerve, allowing a fast, non-invasive way to show possible retinal changes in OSAS patients. Accordingly, retinal changes demonstrated by OCT could function as a window into the brain and can be used as a biomarker [12,33].

As previously reported [13-25], during sleep, intermittent apneic episodes with oxygen desaturation activate proinflammatory and procoagulant mechanisms accompanied by the adrenergic system. These changes promote endothelial dysfunction and oxidative stress with an increase in vascular resistance that, in the end, compromises the optic nerve perfusion and leads to a reduction of retinal thicknesses. These findings can easily be shown with OCT.

A meta-analysis presented by $\mathrm{Yu}$ et al. reviewing 10 case-control studies and another one by Wang et al., including 17 studies on OCT in OSAS, show that the average RNFL thickness in OSAS patients is significantly reduced compared to healthy controls $[22,23]$. In addition, they proposed OCT as a valuable tool to monitor and assess the severity of OSAS in patients, as can be seen in table 5 .

Table 5. OCT findings in OSA patients. RNFL: retinal nerve fiber layer. UAS: upper airway surgery. 


\begin{tabular}{|c|c|c|}
\hline & $\mathbf{N}$ & OCT RETINAL relevant findings \\
\hline Lin et al. (14) & 210 & Peripapillary all quadr. RNFL lower in OSA vs healthy subjects \\
\hline Sagiv et al. (19) & 108 & Peripapillary all quadr. RNFL lower in OSA vs healthy subjects \\
\hline Casas et al. (15) & 96 & Only peripapillary nasal RNFL lower in OSA vs healthy subjects \\
\hline Adam et al. (16) & 43 & No differences between OSA and healthy subjects \\
\hline Kücük et al. (34) & 45 & No differences between OSA and healthy subjects \\
\hline Yu et al. (24) & 69 & Average RNFL thickness lower in severe OSA \\
\hline Ngoo et al. (34) & 44 & Peripapillary all quadr. RNFL lower in OSA vs healthy subjects \\
\hline Guven et al. (35) & 31 & Average nasal RNFL thickness lower in severe OSA \\
\hline \multirow[t]{2}{*}{ Tejero-Garcés et al. } & 98 & Average RNFL thickness lower in severe OSA \\
\hline & $\mathbf{N}$ & OCT OPTIC NERVE relevant findings \\
\hline Lin et al. (14) & 210 & Peripapillary all quadr. RNFL decreased in OSA vs healthy subjects \\
\hline Casas et al. (15) & 96 & Only peripapillary nasal RNFL decreased in OSA vs healthy subjects \\
\hline Kücük et al. (34) & 45 & No differences between OSA and healthy subjects \\
\hline \multirow[t]{2}{*}{ Tejero-Garcés et al. } & 98 & Peripapillary atrophy in severe OSA \\
\hline & $\mathbf{N}$ & OCT as monitor of OSA after treatment \\
\hline Zengin et al. (28) & 44 & After CPAP, all quadr. RNFL decreased compared to controls \\
\hline Lin et al. (29) & 32 & After CPAP, inferior and nasal-inf quadr. RNFL improved compared to controls \\
\hline Lin et al. (30) & 108 & After UAS, macular thickness improved compared to controls \\
\hline Kaya et al. (31) & 34 & After pharyngoplasty, no significant changes \\
\hline Naranjo-Bonilla et al. (37) & 40 & After CPAP, normalization of choroidal thickness \\
\hline Jayakumar et al. (38) & 36 & After UAS and CPAP, choroidal thickness and vascularity improved \\
\hline Tejero-Garcés et al. & 98 & $\begin{array}{l}\text { After UAS and CPAP, foveal thickness and retinal nerve fibers improved in } \\
\text { severe OSA compared to controls }\end{array}$ \\
\hline
\end{tabular}

Lin et al. [14], Sagiv et al. [19], and Ngoo et al. [34] observed a decrease in the average peripapillary RNFL thickness and the superior, inferior, and temporal quadrant thicknesses in OSAS patients compared to those in healthy subjects. On the contrary, Casas et al. [15] and Guven et al. [35] found a decrease of the RNFL thickness just in the nasal quadrant in OSAS patients, whereas Adam et al. [16 and] Kücük et al. [34] did not find any significant difference in RNFL thickness between OSAS patients and healthy controls. In the present study, we observed baseline macular and average RNFL thicknesses were significantly lower in severe OSAS than in mild-moderate OSAS, as found by $\mathrm{Yu}$ et al. [24]. Our findings in severe cases may result from the long-term oxidative process in OSAS, as our patients have been recruited after having apneas for more than two years, compared to less severe cases.

Regarding optic nerve parameters in OCT, Lin et al. [14], Casas et al. [15], and Uslu et al. [26] have reported a greater excavation optic nerve head area (cup area) in OSAS patients than in controls. Kücük et al. [36] have shown that the lamina cribosa thickness was significantly thinner in OSAS patients than in controls. On the contrary, Moyal et al. [27] could not find significant differences between OSAS patients and controls. In this present study, baseline OCT results have been compatible with the theory of neurovascular damage caused by hypoxia: swelling was observed in the retina of mild-moderate OSAS patients, as opposed to atrophy and more significant excavation in severe OSAS ones.

Recently, OCT has been used to monitor the effect of CPAP or surgical treatment for OSAS, showing its utility to check improvements in the retina and optic nerve measurements [28-31]. Zengin et al. [28] studied 44 OSAS patients treated with CPAP, who were followed during a whole year with OCT examinations every three months and compared those results to those of healthy subjects. Baseline OCT data showed no differences between both samples; however, following one year of CPAP therapy, a lower average peripapillary RNFL and nasal, inferior, and superior quadrants thicknesses were described in the patients with OSAS group as compared to the control group. They also studied the correlation between the AHI and the RNFL thickness, observing a weak negative correlation. 
Similarly, Lin et al. [29] have presented a prospective study on 32 OSAS patients treated with CPAP that underwent an OCT three months after treatment. They found that the inferior quadrant and nasal-inferior sector of RNFL thickness significantly improved after treatment. In addition, the macula layer thickness in the superior-inner sector, inferior-outer sector, nasal-outer sector, superior hemisphere, and inferior hemisphere were also significantly improved after treatment. The improvement of macular layer thickness in the superior-inner sector positively correlated with the AHI and desaturation index improvements. Naranjo-Bonilla et al. [37] have recently reported a prospective study including 28 patients treated with CPAP and 12 untreated, showing again normalization of the choroidal thickness measured by OCT in treated patients.

Lin et al. [30] presented a prospective study on 108 OSAS patients treated with upper airway surgery that were monitored by polysomnographic findings and OCT. the thickness of macular layer in the nasal-outer, superior-inner, temporal-inner, inferior-inner, nasal-inner sectors, and total macular layer thickness significantly increased 6 months after upper airway surgery in the severe OSAS group. On the contrary, Kaya et al. [31] have presented a prospective study on 34 OSAS patients treated with expansion sphincter pharyngoplasty. After six months, the preoperative and postoperative AHI scores and average oxygen saturation values were significantly different, but there was no significant difference between the preoperative and postoperative RNFL thicknesses.

Jayakumar et al. [38] have published a prospective study including 36 patients, comparing CPAP, uvulopalatopharyngoplastył, and no treatment. They have shown that choroidal thickness and vascularity improved after six months of both surgery and CPAP. Our study also found an improvement in OCT findings in severe OSAS patients after CPAP or surgical treatment. However, we did not obtain any correlation between changes in the AHI and changes in the OCT after surgical treatment. The most relevant finding in our study is that foveal thickness and retinal nerve fibers (RNFL) average thickness improved after six months of treatment in severe cases. That is, treatment can improve the retinal consequences of OSAS. However, we could not find improvements in optic nerve parameters. Again, this reinforces the need to treat all OSAS patients early to avoid irreversible changes such optic nerve ones.

Lastly, this study has some limitations. First, the research being a single-center study and its small sample size could be considered the main limitation of the present study. Besides, this was not a random trial; however, well-matched groups of patients were studied and provided data on the 6-months follow-up of OSAS treatment effects. We accepted a possible asymmetric affection of the CNS by OSAS, ignoring an interocular correlation in the same patient [39]. However, our baseline results did not show such deviation between sides. Also, a more extended follow-up period could have given us more significant results; nevertheless, both were enough to provide clinically relevant outcomes in our study. Nevertheless, these findings should be supported by large-scale studies.

In conclusion, the present study demonstrated that OCT is an objective method of diagnosis that can inform us about OSAS patients' clinical situation in an easy and noninvasive way by studying the retinal structure. As recent reviews also confirm [40,41], OCT could be useful to undertake the follow-up of the treatment of this disorder, showing retinal changes that help monitor endothelial dysfunction in OSAS, such as foveal thickness and retinal nerve fibers average thickness. In severe OSAS, retina thickness increased six months after treatment. For these reasons, a complete ophthalmic examination should be performed at every follow-up for OSAS patients.

\section{Supplementary Materials:}

Author Contributions: Conceptualization: GTG,FJA,EV. Data curation: GTG,MIA,PC. Formal analysis: GTG,GP. Funding acquisition: Not applicable. Investigation: GTG,PC,EV. Methodology: GTG,FJA,EV,GP. Project administration: GTG. Resources: GTG,FJA,EV. Software: GTG,PC. Supervision: EV,PB,COR,GP. Validation: EV,PB,COR,GP . Visualization: EV,PB,COR,GP. Writing - original draft: GTG,PC. Writing - review \& editing: GTG,EV,PB,COR,GP. 
Funding: This research received no funding.

Institutional Review Board Statement: The study was conducted according to the guidelines of the Declaration of Helsinki, and protocol was approved by the Internal Review Board of the Hospital Miguel Servet. IRB approval was obtained at IRB of Aragon (CEICA) on 13-02-2013 (Act 03/2013) and presented as PhD on January 15th 2016.

Informed Consent Statement: All participants provided written informed consent before the study.

Data Availability Statement: Data are contained within the article.

Conflicts of Interest: The authors declare no conflict of interest regarding the publication of this paper.

\section{References}

1. Gottlieb, D. J., \& Punjabi, N. M. Diagnosis and Management of Obstructive Sleep Apnea: A Review. JAMA. 2020, 323(14), 1389-1400. https://doi.org/10.1001/jama.2020.3514

2. Peppard, P. E., Young, T., Barnet, J. H., Palta, M., Hagen, E. W., \& Hla, K. M. Increased prevalence of sleep-disordered breathing in adults. Am. J. Epidemiol. 2013, 177(9), 1006-1014. https://doi.org/10.1093/aje/kws342

3. Marin, J. M., Carrizo, S. J., Vicente, E., \& Agusti, A. G. Long-term cardiovascular outcomes in men with obstructive sleep apnoea-hypopnoea with or without treatment with continuous positive airway pressure: an observational study. Lancet 2005, 365(9464), 1046-1053. https://doi.org/10.1016/S0140-6736(05)71141-7

4. Vicente, E., Marin, J. M., Carrizo, S. J., Osuna, C. S., González, R., Marin-Oto, M., Forner, M., Vicente, P., Cubero, P., Gil, A. V., \& Soler, X. Upper airway and systemic inflammation in obstructive sleep apnoea. Eur. Resp. J. 2016, 48(4), $1108-1117$. https://doi.org/10.1183/13993003.00234-2016

5. Lloberes, P., Durán-Cantolla, J., Martínez-García, M. Á., Marín, J. M., Ferrer, A., Corral, J., Masa, J. F., Parra, O., Alonso-Álvarez, M. L., Terán-Santos, J. Diagnosis and treatment of sleep apnea-hypopnea syndrome. Spanish Society of Pulmonology and Thoracic Surgery. Arch. Broconeumol. 2011, 47(3), 143-156. https://doi.org/10.1016/j.arbres.2011.01.001

6. Mediano, O., González Mangado, N., Montserrat, J. M., Alonso-Álvarez, M. L., Almendros, I., Alonso-Fernández, A., Barbé, F., Borsini, E., Caballero-Eraso, C., Cano-Pumarega, I., de Carlos Villafranca, F., Carmona-Bernal, C., Carrillo Alduenda, J. L., Chiner, E., Cordero Guevara, J. A., de Manuel, L., Durán-Cantolla, J., Farré, R., Franceschini, C., Gaig, C., ... el Spanish Sleep Network. International Consensus Document on Obstructive Sleep Apnea. Arch. Broconeumol. 2021, S0300-2896(21)00115-0. Advance online publication. https://doi.org/10.1016/j.arbres.2021.03.017

7. Epstein, L. J., Kristo, D., Strollo, P. J., Jr, Friedman, N., Malhotra, A., Patil, S. P., Ramar, K., Rogers, R., Schwab, R. J., Weaver, E. M., Weinstein, M. D., Adult Obstructive Sleep Apnea Task Force of the American Academy of Sleep Medicine. Clinical guideline for the evaluation, management and long-term care of obstructive sleep apnea in adults. J. Clin. Sleep Med. 2009, 5(3), $263-276$.

8. Macey, P. M., Kumar, R., Woo, M. A., Valladares, E. M., Yan-Go, F. L., Harper, R. M. Brain structural changes in obstructive sleep apnea. Sleep 2008, 31(7), 967-977.

9. Purvin, V. A., Kawasaki, A., Yee, R. D. Papilledema and obstructive sleep apnea syndrome. Arch. Ophthalmol. 2000, 118(12), 1626-1630. https://doi.org/10.1001/archopht.118.12.1626

10. Canessa, N., Castronovo, V., Cappa, S. F., Aloia, M. S., Marelli, S., Falini, A., Alemanno, F., Ferini-Strambi, L. Obstructive sleep apnea: brain structural changes and neurocognitive function before and after treatment. Am. J. Respir. Crit. Care Med. 2011, 183(10), 1419-1426. https://doi.org/10.1164/rccm.201005-0693OC

11. Yeung A. Morphometric and functional connectivity changes in the brain of patients with obstructive sleep apnea: A metaanalysis. J. Sleep Res. 2019, 28(6), e12857. https://doi.org/10.1111/jsr.12857

12. Satue, M., Obis, J., Rodrigo, M. J., Otin, S., Fuertes, M. I., Vilades, E., Gracia, H., Ara, J. R., Alarcia, R., Polo, V., Larrosa, J. M., Pablo, L. E., Garcia-Martin, E. Optical Coherence Tomography as a Biomarker for Diagnosis, Progression, and Prognosis of Neurodegenerative Diseases. J. Ophthalmol. 2016, 2016, 8503859. https://doi.org/10.1155/2016/8503859

13. Kargi, S. H., Altin, R., Koksal, M., Kart, L., Cinar, F., Ugurbas, S. H., Ayoglu, F. Retinal nerve fibre layer measurements are reduced in patients with obstructive sleep apnoea syndrome. Eye (Lond). 2005, 19(5), 575-579. https://doi.org/10.1038/sj.eye.6701582

14. Lin, P. W., Friedman, M., Lin, H. C., Chang, H. W., Pulver, T. M., Chin, C. H. Decreased retinal nerve fiber layer thickness in patients with obstructive sleep apnea/hypopnea syndrome. Graefes Arch. Clin. Exp. Ophthalmol. 2011, 249(4), 585-593. https://doi.org/10.1007/s00417-010-1544-1

15. Casas, P., Ascaso, F. J., Vicente, E., Tejero-Garcés, G., Adiego, M. I., Cristóbal, J. A. Retinal and optic nerve evaluation by optical coherence tomography in adults with obstructive sleep apnea-hypopnea syndrome (OSAHS). Graefes Arch. Clin. Exp. Ophthalmol. 2013, 251(6), 1625-1634. https://doi.org/10.1007/s00417-013-2268-9

16. Adam, M., Okka, M., Yosunkaya, S., Bozkurt, B., Kerimoğlu, H., Turan, M. The evaluation of retinal nerve fiber layer thickness in patients with obstructive sleep apnea syndrome J. Ophthalmol. 2013, 2013, 292158. https://doi.org/10.1155/2013/292158

17. Ferrandez, B., Ferreras, A., Calvo, P., Abadia, B., Fogagnolo, P., Wang, Y., Marin, J. M., Iester, M. Retinal sensitivity is reduced in patients with obstructive sleep apnea. Invest. Ophthalmol. Vis. Sci. 2014, 55(11), 7119-7125. https://doi.org/10.1167/iovs.1414389 
18. Hwang, Y. H., Song, M., Kim, Y. Y., Yeom, D. J., Lee, J. H. Interocular symmetry of retinal nerve fibre layer thickness in healthy eyes: a spectral-domain optical coherence tomographic study. Clin. Exp. Optom. 2014,97(6), 550-554. https://doi.org/10.1111/cxo.12218

19. Sagiv, O., Fishelson-Arev, T., Buckman, G., Mathalone, N., Wolfson, J., Segev, E., Peled, R., Lavi, I., Geyer, O. Retinal nerve fibre layer thickness measurements by optical coherence tomography in patients with sleep apnoea syndrome. Clin. Exp. Ophthalmol. 2014, 42(2), 132-138. https://doi.org/10.1111/ceo.12145

20. Xin, C., Wang, J., Zhang, W., Wang, L., Peng, X. Retinal and choroidal thickness evaluation by SD-OCT in adults with obstructive sleep apnea-hypopnea syndrome (OSAS). Eye (Lond). 2014, 28(4), 415-421. https://doi.org/10.1038/eye.2013.307

21. Bayhan, H. A., Aslan Bayhan, S., İntepe, Y. S., Muhafiz, E., Gürdal, C. Evaluation of the macular choroidal thickness using spectral optical coherence tomography in patients with obstructive sleep apnoea syndrome. Clin. Exp. Ophthalmol. 2015, 43(2), 139-144. https://doi.org/10.1111/ceo.12384

22. Yu, J. G., Mei, Z. M., Ye, T., Feng, Y. F., Zhao, F., Jia, J., Fu, X. A., Xiang, Y. Changes in Retinal Nerve Fiber Layer Thickness in Obstructive Sleep Apnea/Hypopnea Syndrome: A Meta-Analysis. Ophthalmic. Res. 2016, 56(2), 57-67. https://doi.org/10.1159/000444301

23. Wang, W., He, M., Huang, W. Changes of Retinal Nerve Fiber Layer Thickness in Obstructive Sleep Apnea Syndrome: A Systematic Review and Meta-analysis. Curr. Eye Res. 2017, 42(5), 796-802. https://doi.org/10.1080/02713683.2016.1238942

24. Yu, J., Xiao, K., Huang, J., Sun, X., Jiang, C. Reduced Retinal Vessel Density in Obstructive Sleep Apnea Syndrome Patients: An Optical Coherence Tomography Angiography Study. Invest. Ophthalmol. Vis. Sci. 2017,58(9), 3506-3512. https://doi.org/10.1167/iovs.17-21414

25. Mentek, M., Aptel, F., Godin-Ribuot, D., Tamisier, R., Pepin, J. L., Chiquet, C. Diseases of the retina and the optic nerve associated with obstructive sleep apnea. Sleep Med Rev. 2018, 38, 113-130. https://doi.org/10.1016/j.smrv.2017.05.003

26. Uslu, H., Kanra, A. Y., Sarac, S. Structural assessment of the optic nerve in patients with obstructive sleep apnea syndrome: Case-control study. Eur. J. Ophthalmol. 2021, 31(4), 1741-1748. https://doi.org/10.1177/1120672120926859

27. Moyal, L., Blumen-Ohana, E., Blumen, M., Blatrix, C., Chabolle, F., Nordmann, J. P. Parafoveal and optic disc vessel density in patients with obstructive sleep apnea syndrome: an optical coherence tomography angiography study. Graefes Arch. Clin. Exp. Ophthalmol. 2018, 256(7), 1235-1243. https://doi.org/10.1007/s00417-018-3943-7

28. Zengin, M. O., Tuncer, I., Karahan, E. Retinal nerve fiber layer thickness changes in obstructive sleep apnea syndrome: one year follow-up results. Int. J. Ophthalmol. 2014, 7(4), 704-708. https://doi.org/10.3980/j.issn.2222-3959.2014.04.22

29. Lin, P. W., Lin, H. C., Friedman, M., Chang, H. W., Salapatas, A. M., Lin, M. C., Chen, Y. C. Effects of CPAP for patients with OSA on visual sensitivity and retinal thickness. Sleep Med. 2020, 67, 156-163. https://doi.org/10.1016/j.sleep.2019.10.019

30. Lin, P. W., Lin, H. C., Friedman, M., Chang, H. W., Salapatas, A. M., Lin, M. C., Chin, C. H. Effects of OSA Surgery on Ophthalmological Microstructures. Ann. Otol. Rhinol. Laryngol. 2019, 128(10), 938-948. https://doi.org/10.1177/0003489419849082

31. Kaya, H., Pekel, G., Kaya, D., Kara, C. O., Hiraali, M. C. The Effects of Surgical Treatment on Retina-Choroidal Findings in Patients With Obstructive Sleep Apnea Syndrome. Ophthalmic. Surg. Lasers Imaging Retina. 2019, 51(1), 35-42. https://doi.org/10.3928/23258160-20191211-05

32. Shrier, E. M., Adam, C. R., Spund, B., Glazman, S., \& Bodis-Wollner, I. Interocular asymmetry of foveal thickness in Parkinson disease. J. Ophthalmol. 2012, 2012, 728457. https://doi.org/10.1155/2012/728457

33. Ascaso, F.J., Mateo, J., Cabezón, L., Casas, P., Grzybowski, A. Other Neurological Disorders: Migraine, Neurosarcoidosis, Schizophrenia, Obstructive Sleep Apnea-Hypopnea Syndrome and Bipolar Disorder. In: Grzybowski A, Barboni P (eds.). OCT and Imaging in Central Nervous System Diseases. Cham: Springer Nature Switzerland, 2020, 317-342. https://doi.org/10.1007/9783-030-26269-3_15

34. Ngoo, Q. Z., A, N. F., A, B., Wh, W. H. Evaluation of Retinal Nerve Fiber Layer Thickness and Optic Nerve Head Parameters in Obstructive Sleep Apnoea Patients. Korean J. Ophthalmol. 2021, 35(3), 223-230. https://doi.org/10.3341/kjo.2020.0019

35. Guven, S., Kilic, D., Bolatturk, O. F. Thinning of the inner and outer retinal layers, including the ganglion cell layer and photoreceptor layers, in obstructive sleep apnea and hypopnea syndrome unrelated to the disease severity. Int. Ophthalmol. 2021, 41(11), 3559-3569. https://doi.org/10.1007/s10792-021-01937-4

36. Küçük, B., Sırakaya, E., Delibaş, Ş. Posterior segment assessment in patients with obstructive sleep apnea syndrome. Sleep Breath. 2019, 23(3), 997-1005. https://doi.org/10.1007/s11325-019-01837-z

37. Naranjo-Bonilla, P., Muñoz-Villanueva, M. C., Giménez-Gómez, R., Jurado-Gámez, B. Retinal and choroidal thickness measurements in obstructive sleep apnea: impacts of continuous positive airway pressure treatment. Graefes Arch. Clin. Exp. Ophthalmol. 2021, 259(11), 3381-3393. https://doi.org/10.1007/s00417-021-05322-w

38. Jayakumar, K., Bansal, S., Markan, A., Agarwal, A., Bansal, R., Mahajan, S., Agrawal, R., Gupta, V. Reversibility of retinochoroidal vascular alteration in patients with obstructive sleep apnea after continuous positive air pressure and surgical intervention. Indian J. Ophthalmol. 2021, 69(7), 1850-1855. https://doi.org/10.4103/ijo.IJO_3150_20

39. Mwanza, J. C., Durbin, M. K., Budenz, D. L., Cirrus OCT Normative Database Study Group. Interocular symmetry in peripapillary retinal nerve fiber layer thickness measured with the Cirrus HD-OCT in healthy eyes. Am. J. Ophthalmol. 2011, 151(3), 51421.e1.

40. Nakayama, L. F., Tempaku, P. F., Bergamo, V. C., Polizelli, M. U., Santos da Cruz, N. F., Bittencourt, L., Regatieri, C. Obstructive sleep apnea and the retina: a review. J. Clin. Sleep Med. 2021, 17(9), 1947-1952. https://doi.org/10.5664/jcsm.9312 
41. Monteiro-Henriques, I., Rocha-Sousa, A., Barbosa-Breda, J. Optical coherence tomography angiography changes in cardiovascular systemic diseases and risk factors: A Review. Acta Ophthalmol. 2021, 10.1111/aos.14851. Advance online publication. https://doi.org/10.1111/aos.14851 